\title{
Macular circulation in patients with diabetes mellitus with and without arterial hypertension
}

\author{
O Arend, M Rüffer, A Remky
}

\begin{abstract}
Background-Previous fluorescein angiographic studies have shown alterations in the macular microcirculation in patients with diabetes mellitus and arterial hypertension. In both diseases capillary blood velocity was reduced and capillary density decreased. These changes were more pronounced in diabetic patients. We have examined the influence of arterial hypertension in combination with diabetes mellitus.

Methods-62 patients with diabetes mellitus and arterial hypertension (group 1) were matched with patients with diabetes mellitus but without arterial hypertension (group 2, match criteria: ETDRS stage of retinopathy). In all subjects fluorescein angiograms were performed with a scanning laser ophthalmoscope. Macular capillary blood velocity (CBV), perifoveal intercapillary area (PIA), the coefficient of variation of both parameters, the area of the foveal avascular zone (FAZ), and the arteriovenous passage time (AVP) were assessed by digital image analysis.
\end{abstract}

Results-Systolic and diastolic blood pressures were significantly increased in the patients with arterial hypertension (systolic $\mathrm{p}=0.0008$; diastolic $\mathrm{p}=0.03$ ). Neither dynamic measures (AVP: 1.64 (0.49) seconds (group 1), $1.72(0.58)$ seconds (group 2); CBV: $1.98(0.39) \mathrm{mm} / \mathrm{s}$ (group 1), $2.09(0.43) \mathrm{mm} / \mathrm{s}$ (group 2)) nor morphological measures (PIA: 7985 (3137) $\mu \mathrm{m}^{2}$ (group 1), 8338 (3376) $\mu \mathrm{m}^{2}$ (group 2); FAZ: 0.319 (0.206) $\mathrm{mm}^{2}$ (group 1), $0.363(0.237) \mathrm{mm}^{2}$ (group 2)) were significantly different between the two groups of diabetic patients.

Conclusion-Arterial hypertension did not result in more severe macular capillary dropout than diabetes without hypertension. This might be explained by the fact that most of the patients were being treated with antihypertensive drugs.

(Br f Ophthalmol 2000;84:1392-1396)

Ophthalmology,

Medical School,

Technical University

Aachen,

Pauwelsstrasse 30, 52057 Aachen,

Germany

O Arend

M Rüffer

A Remky

Correspondence to:

Priv Doz Dr med O Arend

Arend@RWTH-Aachen.de

Accepted 16 June 2000 type of diabetes and the systolic or diastolic blood pressure (BP). ${ }^{1}$
With the introduction of the scanning laser technology, ${ }^{2}$ angiograms of high spatial and temporal resolution can measure simultaneously both dynamic and morphological parameters. In the past, fluorescein angiographic studies in patients with diabetes or hypertension ${ }^{3}{ }^{4}$ have shown reduced capillary blood velocity and decreased capillary density. Enlargement of the area of the foveal avascular zone and the perifoveal intercapillary area, as measures of capillary density, are related to decreased visual acuity ${ }^{5}$ and contrast sensitivity. ${ }^{6}$ Furthermore, in early diabetic angiopathy capillary blood velocities are reduced and the perifoveal intercapillary area is increased before microaneurysm formation occurs. ${ }^{4}$ Thus, digital fluorescein angiography identifies passage of dynamic and morphological changes in the retinal microcirculation of diabetic and hypertensive patients.

Several studies have examined circulatory changes in diabetic patients $\mathrm{s}^{7-10}$ but the effect on the ocular circulation of diabetes mellitus combined with arterial hypertension has not been studied to date. From epidemiological data ${ }^{11}$ one might expect that capillary perfusion is further decreased and capillary density reduced in these patients. Previous microcirculatory studies ${ }^{3-6}$ have shown that measurement of capillary density is a valuable diagnostic tool for differentiating capillary loss. In this study we have used digital fluorescein angiograms to quantify the retinal microcirculation in diabetic patients with and without arterial hypertension. By matching for stage of retinopathy, the effect of diabetes mellitus induced capillary closure has been eliminated and an attempt has been made to define the influence of obstructive hypertensive microangiopathy.

\section{Materials and methods}

Digital recordings of scanning laser videofluorescein angiograms (Scanning Laser Ophthalmoscope; Rodenstock Instruments, Munich, Germany) and image analysing technology (PC) allow measurements of arteriovenous passage times (AVP), mean capillary blood velocity (CBV), the perifoveal intercapillary area (PIA), and the foveal avascular zone (FAZ). In brief, the CBV is determined by measuring the velocities of hypofluorescent particles through the parafoveal vasculature (PC, self-developed software). These particles are presumed to be rouleaux formations of red blood cells. ${ }^{12}$ The AVP time characterises the shortest passage from the dye arriving in the artery, passing through the capillary vasculature, and arriving in the corresponding vein. ${ }^{13}$ The AVP time is correlated with the macular 

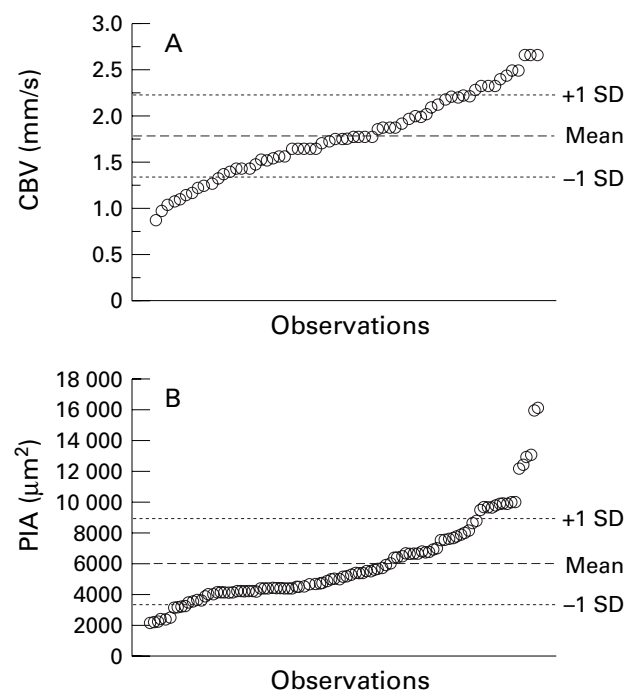

Figure 1 (A) Capillary blood velocity $(C B V)$ and $(B)$ perifoveal intercapillary area (PIA) in a patient with diabetes mellitus showing means and standard deviations.

capillary velocities as demonstrated in healthy subjects. ${ }^{13}$

The PIA provides an estimate of capillary density in the network around the FAZ ( $5^{\circ}$ circle centred over the FAZ). ${ }^{5}$ The borders of these intercapillary areas are marked interactively by drawing the surrounding capillaries with the cursor in the digital image. The area described by the cursor is calculated with the picture analysing system (Matrox Inspector 2.1, Matrox Electronic Systems Ltd, Quebec, Canada). One hundred randomly selected areas surrounded by capillaries are marked and the mean area is calculated from these measurements for each patient. The size of the FAZ is assessed using the same procedure. ${ }^{5}$

All coefficients of variation ( $\mathrm{CV}=\mathrm{SD} /$ mean) for CBV and PIA measurements for each subject were calculated. The mean coefficients of variation $(\mathrm{CV}(\mathrm{CBV}), \mathrm{CV}(\mathrm{PIA}))$ characterise the homogeneity of the perifoveal microcirculation and morphological features of each group. ${ }^{4}$ Figures $1 \mathrm{~A}$ and $\mathrm{B}$ illustrate the distribution of PIA and $\mathrm{CBV}$ in a single patient. All data were corrected for individual refractive error using axial length (A scan ultrasonography) and keratometry. ${ }^{14}$

\section{PATIENTS}

Fluorescein angiograms were performed in 62 diabetic patients with arterial hypertension (group 1; 11 with insulin dependent diabetes mellitus (IDDM) and 51 with non-insulin dependent diabetes mellitus (NIDDM)) and in 62 diabetic patients without arterial hypertension (group 2, 20 IDDM, 42 NIDDM). The two groups were matched for stage of retinopathy. On the basis of the ETDRS classification ${ }^{15}$ the patients were assigned by standardised fundus photography to the following groups: $\mathrm{S} 10$ (no retinopathy), $\mathrm{n}=4 ; \mathrm{S} 20$ (microaneurysms only), $\mathrm{n}=6$; S35 (mild nonproliferative diabetic retinopathy (NPDR)), $\mathrm{n}=8 ; \mathrm{S} 43$ (moderate NPDR), $\mathrm{n}=18 ; \mathrm{S} 53$ (severe NPDR), $\mathrm{n}=9$; $\mathrm{S} 61$ (mild proliferative retinopathy), $\mathrm{n}=8$; $\mathrm{S} 71$ (proliferative retin- opathy with high risk characteristics), $\mathrm{n}=9$. The patients with severe non-proliferative or proliferative retinopathy underwent the angiographic study before pan-retinal photocoagulation. The diagnosis of arterial hypertension was based on repeated readings of $>160 \mathrm{~mm} \mathrm{Hg}$ systolic $\mathrm{BP}$ and $>95 \mathrm{~mm} \mathrm{Hg}$ diastolic BP. The patients with arterial hypertension exhibited only mild vascular alterations corresponding to stages 0 to II described by Scheie. ${ }^{16}$ Forty three $(70 \%)$ patients in group 1 were treated with an antihypertensive drug, 31 $(72 \%)$ with a single drug $(\beta$ blocker, $n=3$; diuretics, $n=11$; calcium channel blocker, $n=11$; ACE inhibitor, $n=6)$, eight (19\%) with a combination of two drugs, and four (9\%) with three or more agents. A total of 19 patients $(30 \%)$ had no antihypertensive drug therapy. To determine the influence of antihypertensive medication these 19 patients (group A) were compared with matched patients without arterial hypertension (group B). The match criterion again was the stage of diabetic retinopathy.

Informed consent was obtained from all patients before participation in the study. The protocol was approved by the human study committee of the Technical University of Aachen and followed the tenets of the Helsinki declaration. Exclusion criteria included lenticular or corneal diseases precluding detailed angiographic study. In addition, patients with allergic disease or history of sensitivity to fluorescein were excluded.

Best corrected visual acuity was determined by an ophthalmologist followed by a complete ophthalmological examination. The studied eye was selected at random if both qualified for the study. These eyes were then studied by fluorescein angiography using the scanning laser ophthalmoscope. Blood pressure (BP) and heart rate were measured before examination with an automatic device (Criticare Vital Daten Monitor, Criticon Inc, Tampa, FL, USA) in the sitting position after 5 minutes of rest. The mean arterial pressure was calculated as one third pulse pressure plus the diastolic (diast) pressure (BPdiast + (BPsyst-BPdiast)/ 3)). ${ }^{17}$

DATA ANALYSIS

Mean values and standard deviations are given for all samples with normal distribution (Kolmogorov-Smirnov test). The Student's $t$ test was used for paired and unpaired samples with normal distribution. Findings with an error probability of $<0.05$ were considered to be statistically significant. Pearson correlation coefficients were calculated to evaluate the relationship between the parameters. $p$ Values were obtained after carrying out Fisher's $r$ to $z$ transformations.

\section{Results}

The clinical and demographic data of the two groups of patients are shown in Table 1. The patients in group 1 had a higher mean age $(\mathrm{p}<0.0001 ; 24 \%)$, higher systolic $(\mathrm{p}=0.0008$; $12 \%)$ and diastolic BP $(\mathrm{p}=0.03 ; 10 \%)$, and higher mean arterial pressure $(p=0.002 ; 8 \%)$ 
Table 1 Mean (SD) clinical and demographic data of diabetic patients with (group 1) and without arterial hypertension (group 2)

\begin{tabular}{llllllll}
\hline & Age (years) & $\begin{array}{l}\text { Sex } \\
(M / F)\end{array}$ & $\begin{array}{l}\text { Systolic BP } \\
(\mathrm{mm} \mathrm{Hg})\end{array}$ & $\begin{array}{l}\text { Diastolic BP } \\
(\text { mm Hg) }\end{array}$ & $\begin{array}{l}\text { Mean arterial } \\
\text { pressure }(m m \\
\text { Hg })\end{array}$ & $\begin{array}{l}\text { Duration of } \\
\text { diabetes (years) }\end{array}$ & Hb $A_{1 c}(\%)$ \\
\hline Group 1 & $54.5(10)$ & $36 / 26$ & $150(21)$ & $87(13)$ & $108(13)$ & $15(8)$ & $8.4(1.6)$ \\
Group 2 & $41.4(13)$ & $36 / 26$ & $132(13)$ & $78(9)$ & $100(14)$ & $16(6)$ & $8.6(1.6)$ \\
Significance $^{\star}$ & $\mathrm{p}<0.0001$ & $\mathrm{NS} \dagger$ & $\mathrm{p}=0.0008$ & $\mathrm{p}=0.03$ & $\mathrm{p}=0.002$ & $\mathrm{NS}$ & $\mathrm{NS}$ \\
\hline
\end{tabular}

«Unpaired Student's $t$ test.

$+\chi^{2}$ test.

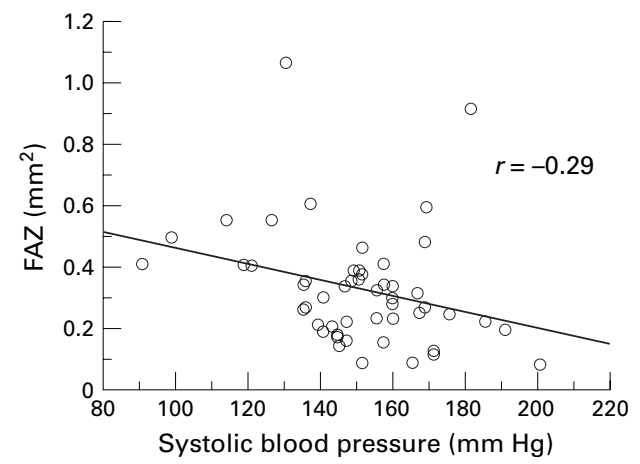

Figure 2 Regression curve of the size of the foveal avascular zone (FAZ) and the systolic blood pressure in patients with diabetes with arterial hypertension.

than patients in group 2. The number of patients with IDDM or NIDDM in the two groups did not differ significantly from each other $\left(\chi^{2}\right.$ test $)$.

Correlation analysis of the microcirculatory data (AVP, CBV, CV(CBV), PIA, CV(PIA), FAZ) with age, systolic BP, diastolic BP, mean arterial pressure, and heart rate showed a weak significant negative correlation between the size of the FAZ and systolic BP $(r=-0.29$, $\mathrm{p}=0.03$; Fig 2$)$ and mean arterial BP $(r=-0.3$, $\mathrm{p}=0.03$ ) only in patients in group 1 . With increasing stage of diabetic retinopathy there was a significant increase in PIA $(p=0.0002)$ and FAZ ( $p=0.03)$, but no interaction was seen between the presence or absence of arterial hypertension and any of the morphological or dynamic parameters measured (ANOVA).

No significant differences were seen between patients in groups 1 and 2 in either the dynamic (AVP 1.64 (0.49) seconds $v 1.72$ (0.58) seconds; CBV $1.98(0.39) \mathrm{mm} / \mathrm{s} v 2.09$ (0.43) $\mathrm{mm} / \mathrm{s}$; CV(CBV) 16.9 (7)\% v 17 (7)\%) or the morphological parameters (PIA 7985 (3137) $\mu \mathrm{m}^{2} v 8338$ (3376) $\mu \mathrm{m}^{2}$; CV(PIA) 66 (33) $\%$ v 70 (32)\%; FAZ $0.319(0.206) \mathrm{mm}^{2} v$ $\left.0.363(0.237) \mathrm{mm}^{2}\right)$.

Compared with reference data in healthy subjects $^{513}$ (AVP 1.58 (0.4) seconds, CBV $2.83(0.3) \mathrm{mm} / \mathrm{s}$; CV(CBV) 12 (5)\%; PIA

Table 2 Microcirculatory results of diabetic patients with untreated arterial hypertension $(n=19 ;$ group $A)$ and matched normotensive diabetic patients $(n=19$; group $B)$

\begin{tabular}{llll}
\hline & Group $A$ & Group $B$ & Significance $^{*}$ \\
\hline AVP $(\mathrm{s})$ & $1.73(0.57)$ & $1.75(0.62)$ & NS \\
CBV $(\mathrm{mm} / \mathrm{s})$ & $2.0(0.41)$ & $2.0(0.37)$ & NS \\
CV $(\mathrm{CBV})(\%)$ & $15.9(6.3)$ & $15.6(5.3)$ & NS \\
FAZ $\left(\mathrm{mm}^{2}\right)$ & $0.302(0.11)$ & $0.267(0.09)$ & NS \\
PIA $\left(\mu^{2}\right)$ & $7015(1726)$ & $6522(2596)$ & NS \\
CV $($ PIA $)(\%)$ & $66.8(43.1)$ & $64.3(27.0)$ & NS \\
\hline
\end{tabular}

$\mathrm{AVP}=$ arteriovenous passage time $\mathrm{CBV}=$ capillary blood velocity $\mathrm{CV}(\mathrm{CBV})=$ mean coefficient of variation of capillary blood velocity; PIA $=$ perifoveal intercapillary area; $\mathrm{CV}(\mathrm{PIA})=$ mean coefficient of variation of perifoveal intercapillary area; FAZ = area of foveal avascular zone.

$\star$ Unpaired Student's $t$ test.
3686 (345) $\mu \mathrm{m}^{2}, \mathrm{CV}(\mathrm{PIA}) 34$ (8)\%; FAZ $\left.0.205(0.062) \mathrm{mm}^{2}\right)$, both groups with diabetic retinopathy showed significantly prolonged AVP times $(\mathrm{p}<0.0001)$, decreased CBV $(p<0.0001)$, increased coefficients of variation (CV(CBV): $\mathrm{p}=0.0001$ (group 1), $\mathrm{p}=0.0007$ (group 2); CV(PIA): $\mathrm{p}<0.0001$ ), as well as increased FAZ area $(\mathrm{p}<0.0001)$ and PIA $(\mathrm{p}<0.0001)$.

The effect of antihypertensive medication on retinal circulation was studied in 19 diabetic patients with arterial hypertension receiving no antihypertensive medication (group A) and a group of 19 normotensive diabetic patients matched for stage of retinopathy (group B). There were no significant differences between the two groups for age (54 (9) v 47 (18) years), duration of diabetes (9.6 (5.7) $v 13.1$ (7.7) years), mean glycosylated haemoglobin $\left(\mathrm{HbA}_{1 \mathrm{C}}\right)(8.0(2.1) \%$ v $8.3(1.4) \%)$, and systolic BP (148 (24) v 143 (23) $\mathrm{mm} \mathrm{Hg}$ ) but significant differences were found in diastolic $\mathrm{BP}$ (93 (16) $v 81$ (17) $\mathrm{mm} \mathrm{Hg}$; $\mathrm{p}=0.04$ ). There were no significant differences in the microcirculatory data tested between the patients in groups A and B (Table 2).

\section{Discussion}

The increased risk of cerebral, cardiovascular, and renal disease resulting from arterial hypertension in patients with diabetes mellitus has been described in various studies. ${ }^{11}{ }^{18-24}$ However, these studies reached different conclusions with regard to the effect of reducing systolic and diastolic BP and the influence of the type of diabetes. The impact of arterial hypertension on diabetic retinopathy is either an increased rate of progression ${ }^{1123-26}$ or it has little or no effect. ${ }^{20} 27-30$

Past studies using scanning laser fluorescein angiography have shown decreased capillary density in patients with arterial hypertension ${ }^{3}$ (PIA $5591(838) \mu \mathrm{m}^{2}$ ) and in those with diabetic retinopathy. ${ }^{4}$ Furthermore, capillary perfusion in the macula region is decreased in diabetic $^{4}$ and in hypertensive ${ }^{3}$ patients. A decrease in perfusion occurs early in diabetes when no microaneurysms are visible and is associated with increased perifoveal intercapillary area as a sign of decreased capillary density. ${ }^{4}$ Various studies have found hyperperfusion or hypoperfusion to be pathogenic in patients with diabetes mellitus. ${ }^{41031-35}$ The effect of decreased perfusion can be explained by progressive capillary closure with increased resistance and decreased perfusion. ${ }^{36}$ Capillary closure is a well established angiographic and histopathological sign of diabetic retinopathy. ${ }^{37}$ Capillary loss, as reflected by the 
perifoveal intercapillary area, is accompanied by early loss of visual function ${ }^{6}$ and represents an in vivo measure of capillary density. The effect of hyperperfusion in diabetes mellitus ${ }^{39}$ may be explained by shear stress of the vessel wall and induction of humoral factors.

Vascular changes resulting from arterial hypertension include a range of changes in the vessel wall ${ }^{16}$ and can result in capillary rarefaction. ${ }^{36}$ In a 2 year angiographic follow up study of hypertensive patients the capillary density remained unchanged. ${ }^{40}$

The present study was designed to examine whether progressive retinal capillary closure with attenuated circulation occurs in patients with diabetes mellitus and arterial hypertension. Both patient groups had prolonged AVP times with decreased CBV and increased FAZ and PIA compared with reference data from healthy subjects. ${ }^{513}$ With increasing stage of diabetic retinopathy there was a significant increase in PIA and FAZ but no interaction was seen between the presence or absence of arterial hypertension and any of the morphological or dynamic parameters measured. This suggests that the capillary closure associated with diabetes mellitus is so dominant that the arterial hypertension results in no additional detectable capillary closure. Furthermore, the mean coefficients of variation $(\mathrm{CV}(\mathrm{CBV})$, CV(PIA)) showed no further heterogeneity in perfusion or capillary density resulting from the presence of arterial hypertension.

Correlation analysis revealed a decrease in FAZ with increasing systolic BP and mean arterial pressure in diabetic patients with arterial hypertension. The significance of this finding was low and further studies are needed to confirm this trend, but it supports the similar vascular patterns seen in diabetic patients with or without arterial hypertension. The fact that the hypertensive group was significantly older did not influence the results. Correlation analysis showed no significant correlation between age and any of the parameters measured.

Since no additional effect on capillary perfusion was found, one could speculate that no changes occurred because the patients were receiving antihypertensive medication. However, no difference in retinal perfusion or capillary density was seen between a group of newly diagnosed hypertensive patients with diabetes mellitus not receiving antihypertensive treatment and a matched population of diabetic patients without arterial hypertension.

In this study the systolic and diastolic BPs were only moderately increased (systolic $150 \mathrm{~mm} \mathrm{Hg}$; diastolic $87 \mathrm{~mm} \mathrm{Hg}$ ). The UKPDS study ${ }^{11}$ found that a reduction in systolic BP to $<150 \mathrm{~mm} \mathrm{Hg}$ and in diastolic $\mathrm{BP}$ to $<85 \mathrm{~mm} \mathrm{Hg}$ led to a significant reduction in the risk of deterioration in visual acuity and retinopathy. Nørgaard et $a l^{28}$ found that arterial hypertension per se is not associated with increased retinal changes, but it may worsen these changes in patients with clinically apparent nephropathy. This suggests that future angiographic studies should be performed in diabetic patients with associated nephropathy or with more severe arterial hypertension.

Presented in part at the 96th Annual Meeting of the Deutsche Ophthalmologische Gesellschaft in Berlin, Germany, 19-22 September 1998 and the Annual Meeting of the Association for Research in Vision and Ophthalmology, Fort Lauderdale, FL, USA, 1999

Supported by Start 4-96 (OA, AR) and Hochschulsonderprogramm III Nordrhein-Westfalen (MR).

Proprietary interests: None

1 Bonnet S, Marechal G. Influence de l'hypertension rtérielle sur la rétinopathie diabétique. $\mathcal{F}$ Maladies Vasculaires 1992;17:308-10.

2 Plesch A, Klingbeil U. Optical characteristics of a scanning laser ophthalmoscope. SPIE 1989;1161:390-8

3 Wolf S, Arend O, Schulte K, et al. Quantification of retinal capillary density and flow velocity in patients with essential hypertension. Hypertension 1994;23:464-7.

4 Arend $\mathrm{O}$, Wolf S, Jung F, et al. Retinal microcirculation in patients with diabetes mellitus: dynamic and morphologic analysis of perifoveal capillary network. $\mathrm{Br} \mathcal{F}$ Ophthalmol 1991;75:514-8.

5 Arend O, Wolf S, Harris A, et al. The relationship of macular microcirculation to visual acuity in diabetic patients. Arch Ophthalmol 1995;113:610-4.

6 Arend O, Remky A, Evans D, et al. Contrast sensitivity loss is coupled with capillary drop-out in diabetic patients with unaffected visual acuity. Invest Ophthalmol Vis Sci 1997;38: unaffected

7 Rimmer T, Fallon TJ, Kohner EM. Long-term follow-up of retinal blood flow in diabetes using the blue light entoptic phenomen. Br F Ophthalmol 1989;73:1-5.

8 Grunwald JE, Brucker AJ, Grunwald SE, et al. Retinal hemodynamics in proliferative diabetic retinopathy. Invest Ophthalmol Vis Sci 1993;34:66-71.

9 Goebel W, Lieb WE, Ho A, et al. Color Doppler imaging: a new technique to assess orbital blood flow in patients with diabetic retinopathy. Invest Ophthalmol Vis Sci 1995;36: 864-70.

10 Bertram B, Wolf S, Fiehöfer S, et al. Retinal circulation times in diabetes mellitus type I. Br f Ophthalmol 1991;75: $462-5$.

11 UK Prospective Diabetes Study Group. Tight blood pressure control and risk of macrovascular and microvascu-
lar complications in type 2 diabetes: UKPDS 38. BMF 1998;317:703-13.

12 Arend O, Harris A, Sponsel WE, et al. Macular capillary particle velocities: a blue field and scanning laser comparison. Graefes Arch Clin Exp Ophthalmol 1995;233:244-9.

13 Wolf S, Arend O, Reim M. Measurement of retinal hemodynamics with scanning laser ophthalmoscopy: reference values and variation. Surv Ophthalmol (Suppl) 1994;38:95100.

14 Littmann H. Zur Bestimmung der wahren Größe eines Objektes auf dem Hintergrund eines lebenden Auges. Klin Mbl Augenheilk 1988;192:66-7.

15 Early Treatment Diabetic Retinopathy Study Research Group. Fundus photographic risk factors for progression of diabetic retinopathy. Early Treatment Diabetic Retinopathy Study Report number 12. Ophthalmology Suppl opathy Study R

16 Murphy RP, Chew EY. Hypertension. In: Ryan SJ, ed. Retina. Volume 2. St Louis: Mosby, 1989:449-55.

17 Rooke TW, Sparks HV. An overview of circulation and hemodynamics. In: Rhoades RA, Tanner GA, eds. Medical physiology. Boston: Little, Brown and Company, 1995:23041 .

18 Hansson L, Zanchetti A, Carruthers SG, et al. Effects of intensive blood pressure lowering and low dose aspirin in patients with hypertension: principal results of the hypertension optimal treatment (HOT) randomized trial. Lancet 1998;351:1755-62.

19 Agardh CD, Agardh E, Torffivit O. The association between retinopathy, nephropathy, cardiavascular disease and longterm metabolic control in type I diabetes mellitus: a 5 year follow-up study of 442 adult patients in routine 5 year Diabetes Res Clin Prac 1997;35:113-21.

20 Araki A, Ito H, Hattori A, et al. Risk factors for development in elderly japanese patients with diabetes mellitus. Diabetes Care 1993;16:1184-6.

21 Knowler WC, Bennett PH, Ballintine EJ. Incresed incidence of retinopathy in diabetics with elevated blood pressure. $N$ Engl f Med 1980;302:645-50.

22 Moss SE, Klein R, Klein BEK. Ten-year incidence of visual loss in a diabetic population. Ophthalmology 1994;101: 1061-70.

23 Chase HP, Garg SK, Jackson WE, et al. Blood pressure and retinopathy in type I diabetes. Ophthalmology 1990;97:155-

24 Janka HU, Warram JH, Rand LI, et al. Risk factors for progression of background retinopathy in long-standing (IDDM). Diabetes 1989;38:460-4

25 Cignarelli M, De Cicco ML, Damata A, et al. High systolic blood pressure increases prevalence and severity of retinopathy in NIDDM patients. Diabetes Care 1992;15: 1002-8.

26 Guillausseau PJ, Massin P, Charles MA, et al. Glycaemic control and development of retinopathy in type 2 diabetes mellitus: a longitudinal study. Diabetic Med 1998;15:151-5. 
27 West KM, Erdreich LJ, Stober JA. A detailed study of risk factors for retinopathy and nephropathy in diabetes.

28 Nørgaard K, Feldt-Rasmussen B, Deckert T. Is hypertension a major independent risk factor for retinopathy in type 1 diabetes? Diabetic Med 1991;8:334-7.

29 Chen MS, Kao CS, Chang CJ, et al. Prevalence and risk factors of diabetic retinopathy among noninsulin-dependent subjects. Am $\mathcal{f}$ Ophthalmol 1992;114:723-30.

30 Klein R, Klein BEK, Moss SE, et al. Is blood pressure a predictor of the incidence or progression of diabetic retinopathy? Arch Intern Med 1989;149:2427-32.

31 Patel V, Rassam S, Newsom R, et al. Retinal blood flow in diabetic retinopathy. BMF 1992;305:678-83.

32 Oswald B, Vilser W, Oswals H, et al. Measurement of flowphysiologic parameters of retinal blood circulation in type 1 and 2 diabetes before and after photocoagulation. Graefes Arch Clin Exp Ophthalmol 1985;223:154-7.

33 Grunwald JE, Brucker AJ, Petrig BL, et al. Retinal blood flow regulation and clinical response to panretinal photocoagulation in proliferative diabetic retinopathy. Ophthalmology 1989;96:1518-22.
34 Feke GT, Buzney SM, Ogasawara H, et al. Retinal circulatory abnormalities in type I diabetes. Invest Ophthalcirculatory abnormalities in typ
mol Vis Sci 1994;35:2968-75.

35 Güven D, Özdemir H, Hasanreisoglu B. Hemodynamic alterations in diabetic retinopathy. Ophthalmology 1996; 03:1245-9.

36 Greene AS, Tonellato PJ, Lui J, et al. Microvascular rarefication and tissue vascular resistance in hypertension. Am $\mathcal{F}$ Physiol 1989;256:126-31.

37 Bresnick GH, Condit R, Syrjala S, et al. Abnormalities of the foveal avascular zone in diabetic retinopathy. Arch Ophthalmol 1984;102:1286-93.

38 Ashton N. Studies of the retinal capillaries in relation to diabetic and other retinopathies. Br f Ophthalmol 1963:47: 521-38.

39 Kohner EM, Patel V, Rassam SMB. Role of blood flow and impaired autoregulation in the pathogenesis of diabetic impaired autoregulation in the patho

40 Kutschbach P, Wolf S, Sieveking M, et al. Retinal capillary density in patients with arterial hypertension: 2 year follow-up. Graefes Arch Clin Exp Ophthalmol 1998;236:4104 . 